\title{
Magnetic resonance guided focused ultrasound for noninvasive pain therapy of osteoid osteoma in children
}

\author{
Adam Waspe ${ }^{1 *}$, Yuexi Huang ${ }^{2}$, Ruby Endre ${ }^{2}$, Joao Amaral ${ }^{1}$, Joost de Ruiter ${ }^{1}$, Fiona Campbell ${ }^{1}$, Charles Mougenot ${ }^{3}$, \\ Kullervo Hynynen², Gregory Czarnota², James Drake ${ }^{1}$, Michael Temple ${ }^{1}$
}

From Current and Future Applications of Focused Ultrasound 2014. 4th International Symposium

Washington, D.C, USA. 12-16 October 2014

\section{Background/introduction}

Osteoid osteoma (OO), a small painful benign bone tumor, is the most common bone tumor in children. Pain is managed with nonsteroidal anti-inflammatory drugs but minimally invasive techniques, such as CT-guided laser ablation, have become a standard intervention. However, the potential for non-target injury is a concern as tissue temperature cannot be measured with $\mathrm{CT}$ and the laser induces temperatures $>90^{\circ} \mathrm{C}$ for 10 minutes. It also includes risks from exposure to ionizing radiation, fracture, infection and transmitted thermal damage from the access needle. Magnetic resonance guided high intensity focused ultrasound (MRgHIFU) has been used successfully in small cohorts of adults with OO. The noninvasive nature of the energy means that procedures do not need to be conducted in a sterile environment since there is no mechanical penetration of the bone, reducing the chance of pathologic fracture and infection.

\section{Methods}

A Philips Sonalleve MRgHIFU device is being used to thermally ablate $\mathrm{OO}$ in pediatric patients. MR provides excellent soft tissue contrast, which enhances the interface between bone and surrounding soft tissues as well as the highly vascularized core of the OO, known as the nidus. The nidus is the primary target of thermal OO treatments since destroying it will prevent regrowth of this painful lesion. Ten patients will be recruited and complete age-appropriate and validated surveys (Pediatric Ouch, and PedsQLTM) to determine how lesion/bone pain and medication usage affects health-related quality of life (HRQL) metrics, such as physical, emotional, social, and school functioning. A planning MRI will be used to ensure lesion accessibility/patient eligibility and MR thermometry will measure temperature in the target and surrounding tissue to ensure patient safety. As thermal bone ablation is painful, patients will be under general anesthesia for the treatment. Follow-up on days 2, 7, 14, 30, 90 and 180 following treatment will record pain, HRQL, and drug usage. Clinical visits on days 30 , 90 and 180 will comprise a physical examination and a diagnostic MRI of the OO. Contrast enhanced MRI will indicate non-perfused tissues corresponding to the ablated tissue volume, which should be fully resolved by day 180 .

\section{Results and conclusions}

One patient with a $1 \mathrm{~cm} \mathrm{OO}$ on the left femoral head is currently enrolled in the study and was treated with MRgHIFU using seven $4 \mathrm{~mm}$ treatment cells (Fig 1). Individual treatments were $12 \mathrm{~s}$ in duration with a power of $40-60 \mathrm{~W}$. Temperatures $>55^{\circ} \mathrm{C}$ were measured at the bone surface and a thermal dose of $240 \mathrm{EM} @ 43^{\circ} \mathrm{C}$ was achieved (Fig 2). A small region of non-perfused tissue was observed in contrast enhanced MRI corresponding to the thermal dose margins (Fig 3). One week after treatment the patient is pain free, off medication, and is consistently sleeping throughout the night. Study assessment of pain, HRQL and medication will follow. It is expected that MRgHIFU will be effective for reducing pain and medication usage, leading to an improvement in HRQL.

${ }^{1}$ Hospital for Sick Children, Toronto, Canada

Full list of author information is available at the end of the article 


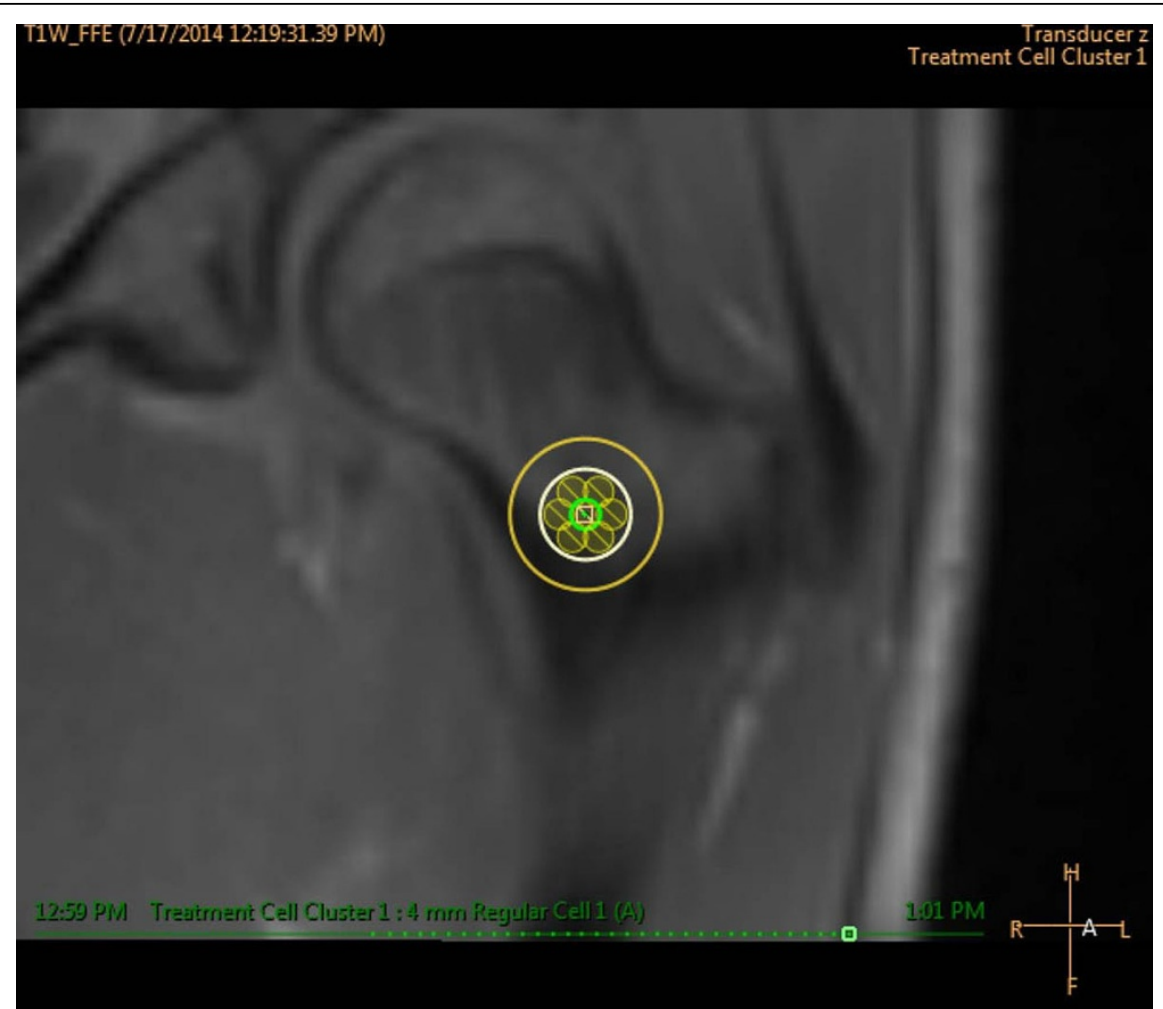

Figure 1 Planned treatment cells to cover the volume of the osteoid osteoma. A total of seven $4 \mathrm{~mm}$ treatment cells, arranged in a circular cluster, covered the extent of the $1 \mathrm{~cm}$ lesion.

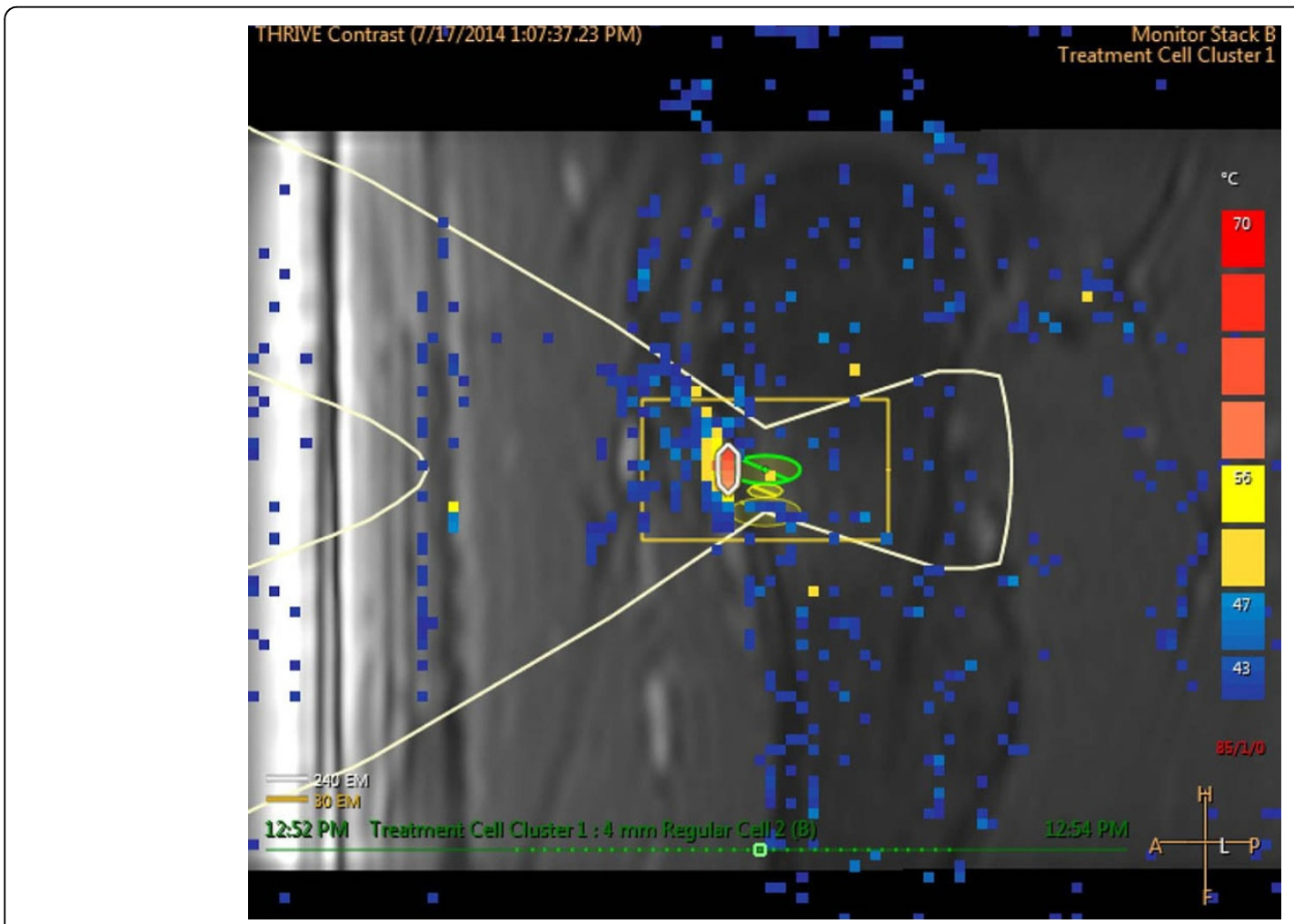

Figure 2 Representative thermal map from one of the treatment sonications. A $50 \mathrm{~W}$ exposure produced a maximum temperature above $55^{\circ} \mathrm{C}$ at the bone surface. A small region (approximately $1 \times 4 \mathrm{~mm}$ ) adjacent to the osteoid osteoma reached sufficient temperatures to achieve a thermal dose of $240 \mathrm{EM} @ 43^{\circ} \mathrm{C}$, causing necrosis. 


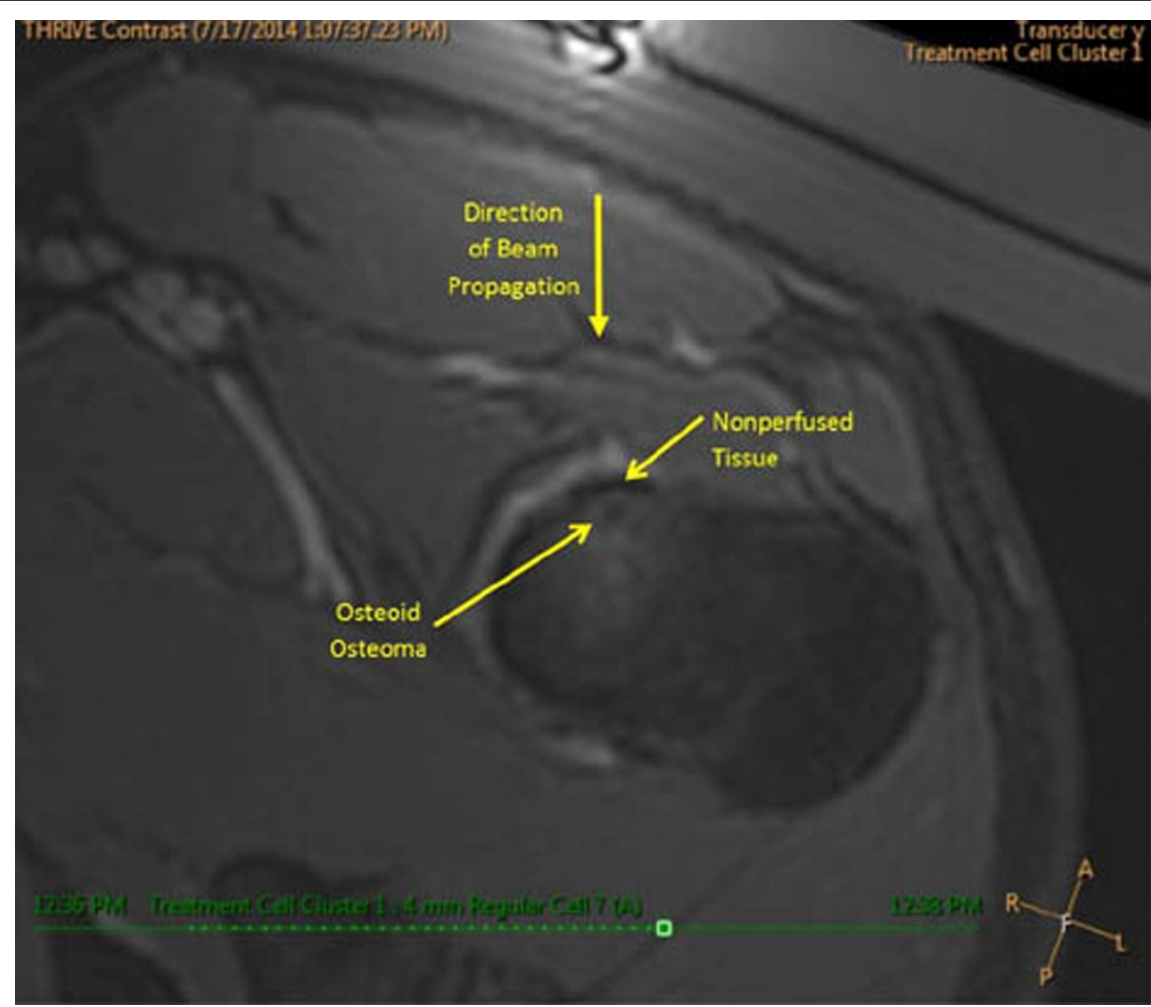

Figure 3 Gadolinium enhanced T1-w image of the osteoid osteoma and treatment area following thermal ablation. A small region of nonperfused tissue is visible at the bone surface, adjacent to the osteoid osteoma lesion that is approximately the same extent as the thermal dose contour.

\section{Acknowledgements (Funding)}

We acknowledge project funding from the Focused Ultrasound Foundation and the Hospital for Sick Children Innovation Fund. This clinical study is not industry sponsored but we do receive technical support from Philips Healthcare and collaborate with Philips on preclinical focused ultrasound projects.

\section{Authors' details}

${ }^{1}$ Hospital for Sick Children, Toronto, Canada. ${ }^{2}$ Sunnybrook Health Sciences Centre, Toronto, Canada. ${ }^{3}$ Philips Healthcare, Toronto, Canada.

Published: 30 June 2015

doi:10.1186/2050-5736-3-S1-048

Cite this article as: Waspe et al:: Magnetic resonance guided focused ultrasound for noninvasive pain therapy of osteoid osteoma in children. Journal of Therapeutic Ultrasound 2015 3(Suppl 1):O48.

\section{Submit your next manuscript to BioMed Central and take full advantage of:}

- Convenient online submission

- Thorough peer review

- No space constraints or color figure charges

- Immediate publication on acceptance

- Inclusion in PubMed, CAS, Scopus and Google Scholar

- Research which is freely available for redistribution

Submit your manuscript at www.biomedcentral.com/submit 